\title{
Pelestarian Identitas Arsitektural Lokal melalui Redesain Terminal Bandar Udara
}

\author{
Dela Erawati dan Nur Endah Nuffida. \\ Jurusan Arsitektur, Fakultas Teknik Sipil dan Perencanaan, Institut Teknologi Sepuluh Nopember \\ (ITS) \\ Jl. Arief Rahman Hakim, Surabaya 60111 \\ E-mail: nuffida@arch.its.ac.id
}

\begin{abstract}
Abstrak-Identitas lokal merupakan sebuah wujud kekayaan dari kearifan lokal. Masing-masing daerah memiliki kearifan lokal yang bermaksud untuk mempertahankan keseimbangan pada daerah tersebut. Sehingga sudah sepatutnya hal tersebut dilestarikan.

Mewujudkan sebuah bentukan yang ikonik pada ruang publik berdasarkan ciri atau identitas khusus suatu daerah merupakan salah satu cara mengabadikan identitas lokal tersebut, terutama saat bentukan hadir sebagai gerbang kota yang menyambut datangnya orang dari luar daerah. Bangunan tersebut menyambut dan menjadi wajah pertama kota tempatnya berada.

Disini kegiatan redesain memiliki tujuan secara khusus untuk memperkenalkan kembali identitas arsitektural khas Papua yang kian hilang melalui sebuah transformasi bentuk serta penyesuaian terhadap tipologi bangunan yang ada.
\end{abstract}

Kata Kunci-Bandar udara, budaya, redesain, ruang publik, Papua.

\section{PENDAHULUAN}

$\mathrm{K}$ ERAGAMAN budaya merupakan sebuah identitas tersendiri terutama bagi bangsa Indonesia secara keseluruhan. Dengan bentangan Indonesia yang luas, keberagaman menimbulkan keuntungan sekaligus kerugian tersendiri. Keuntungan dari luasnya area menciptakan keragaman yang kaya. Namun, karena bentang yang lebar tersebut, sebagian besar rakyat Indonesia sendiri tidak mengetahui seperti apa keadaan Indonesia di luar wilayah yang ditinggalinya.

Globalisasi yang seharusnya menghapuskan batas dan mempernudah penyebaran informasi justru berbalik mengancam kondisi kelestarian budaya yang ada. Kondisi ini tentu merupakan hal yang buruk mengingat banyaknya budaya yang ada dan tidak disebarkan keluar, justru tertekan dengan budaya yang ada dari luar maka akan ada kemungkinan hilang tanpa jejak.

Diperlukan penyelarasan demi kelestarian identitas lokal dalam arus globalisasi yang banyak membawa pengaruh dari luar. Identitas lokal, secara khusus berupa identitas arsitektur lokal, sebagai salah satu bentuk kekayaan arsitektur nusantara mampu diolah melalui proses transformasi. Pengolahan ini bertujuan agar tercipta paduan antara bentukan lokal dan global.

Adapun penerapan identitas arsitektur pada wajah kota ditujukan untuk menjadi penyambut, memperkenalkan sebagian dari keseluruhan identitas daerah yang dimiliki dalam bentuk arsitektural. Wajah kota yang dimaksud disini berupa bandar udara yang merupakan pintu gerbang antar

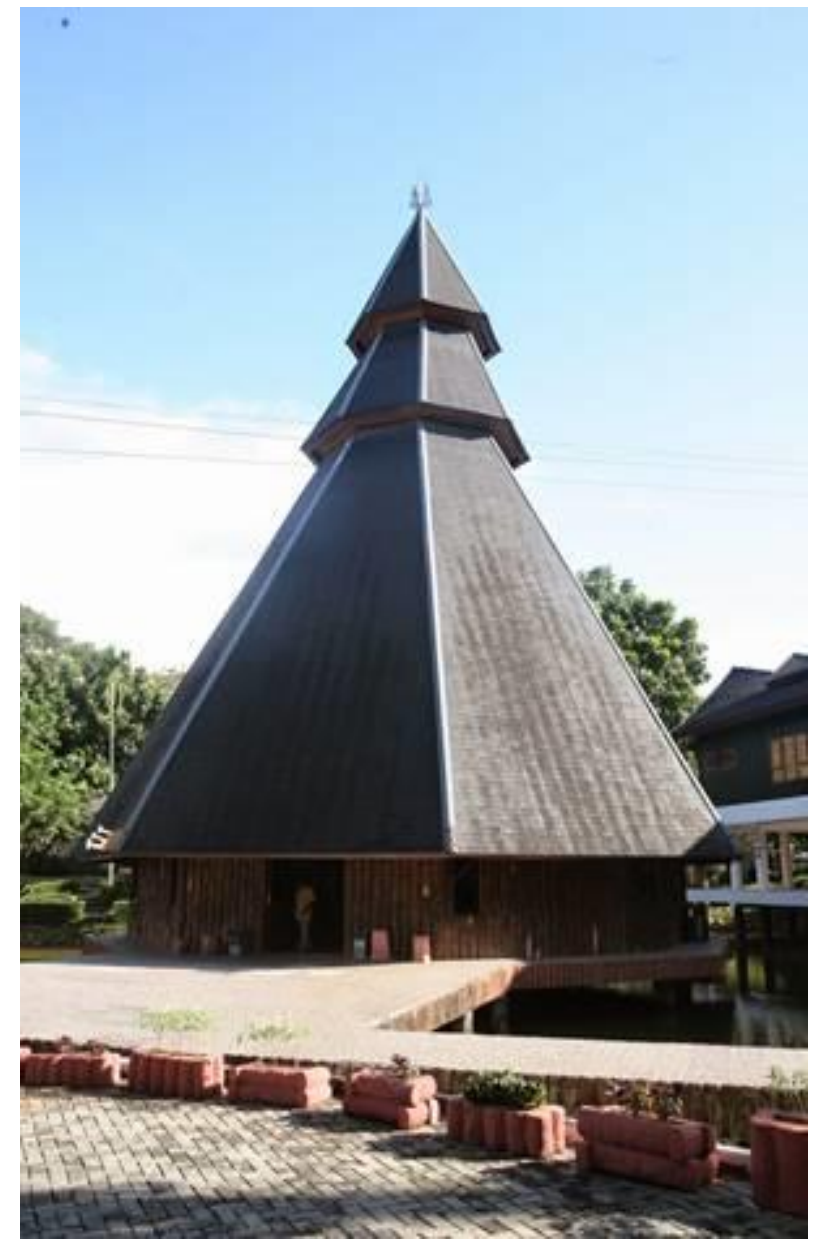

Gambar 1. Rumah Kariwari

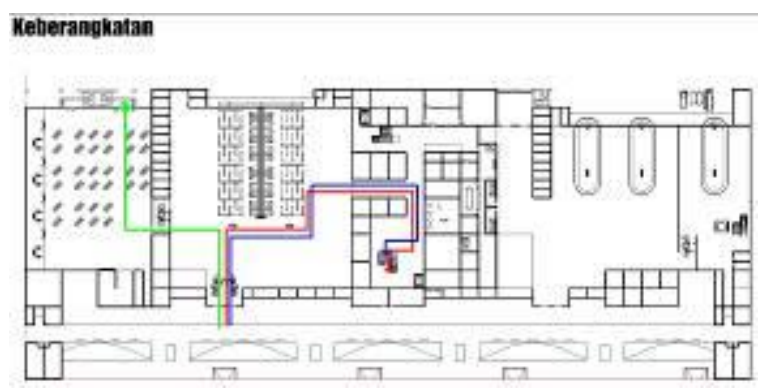

Gambar 2. Alur sirkulasi penumpang (a).

(Sumber: Dok. penulis) 
daerah atau bahkan antar negara. Bangunan terminal bandar udara yang merupakan persinggahan antar destinasi memiliki kesempatan terbaik untuk menjadi cerminan wilayah termpat berdirinya berada.

\section{EKSPLORASI DAN PROSES RANCANG}

\section{A. Optimalisasi}

Bandar udara sebagai pintu masuk sebuah kota sering menjadi kesan pertama dan terakhir suatu daerah pada para penumpang [1]. Hal tersebut tentu mempengaruhi desain sebuah terminal. Sehingga optimalisasi bangunan dijalankan berdasarkan tujuan meningkatkan performa bangunan terminal yang ada.

Berdasarkan data dari Direktorat Jenderal Perhubungan Udara Kementerian Perhubungan Republik Indonesia [2], Bandar Udara Sentani tercatat sebagai bandar udara internasional. Tetapi pada kenyataannya kondisi tersebut tidak didukung dengan fasilitas yang memadai. Sehingga optimalisasi penggunaan lahan dilakukan dalam proses redesain untuk menambahkan fungsi yang belum dilengkapi.

\section{B. Transformasi}

Arsitektur nusantara merupakan seni dan ilmu merancang yang mengacu pada potensi-potensi tradisi dan kebudayaan serta kondisi iklim Indonesia sebagai negara kepulauan.

Suatu rupa atau unsur rupa dapat digubah dengan melakukan pemalihan (transformasi) atau modifikasi terhadap rupa asal [3]. Transformasi dilakukan untuk mengolah bentuk identitas lokal dan menghasilkan bentuk yang baru yang juga menyesuaikan kebutuhan bangunan sebagai terminal. Adapun teknik yang lazim dilakukan dengan merubah ukuran, diperbesar atau diperkecil, diperpanjang atau diperpendek, diperkasar atau diperhalus, dibengkokkan atau diluruskan, diganti warna, dan sebagainya.

\section{PROSES RANCANGAN}

\section{A. Optimalisasi Terminal}

Demi menampung kegiatan yang sebelumnya belum difasilitasi, dilakukan perluasan area terminal. Sirkulasi ruang terminal baru diatur untuk menampung kegiatan terminal penumpang internasional. Hal ini ditandai dengan penambahan ruang tunggu internasional, kantor bea cukai, kantor imigrasi, dan ruang tunggu internasional. Alur penumpang pun berubah seiring penambahan tersebut yang terlihat pada Gambar 2.

\section{B. Transformasi Bangunan Terminal}

Mengambil kondisi Kariwari sebagai rumah budaya atau pembelajaran di dalam gugus bangunannya, ia ditransformasikan dan ditempatkan sebagai poin utama pada tampak bangunan. Limas segi delapan sebagai bentuk dasar Kariwari ditempatkan menyebar sesuai bentang atap untuk memperlihatkan analogi gugus bangunan Kariwari asli dimana rumah berjajar linier dengan jembatan penghubung ditengahnya.

Selain itu, penggantian material dilakukan untuk memasukkan cahaya alami ke dalam bangunan mengingat
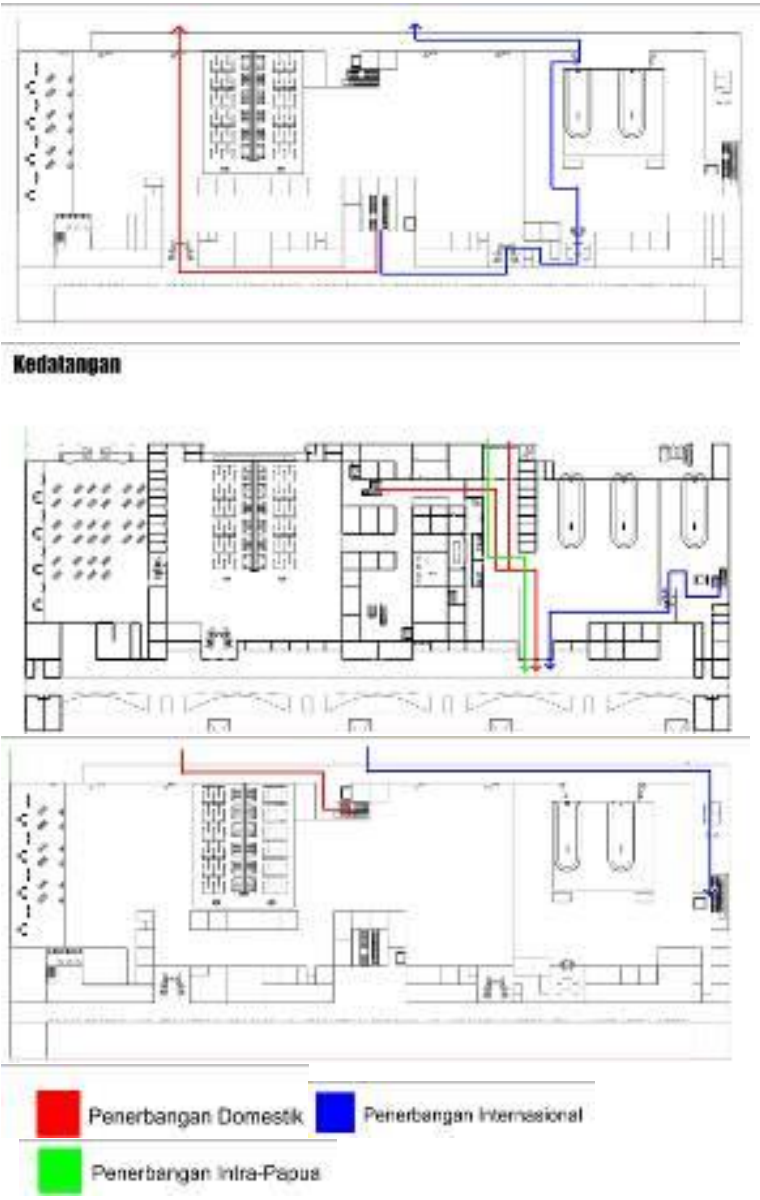

Gambar 2. Alur sirkulasi penumpang (b)
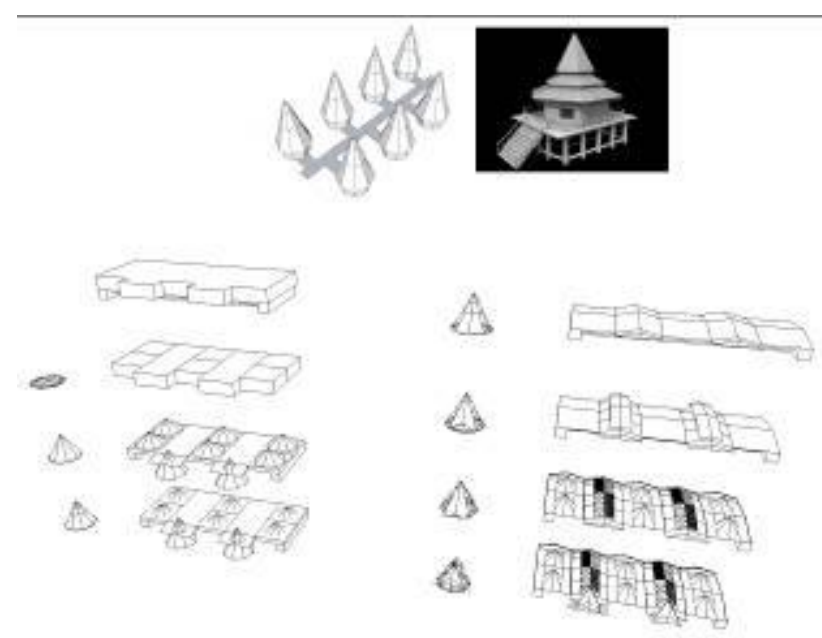

Gambar 3. Proses transformasi bentuk Kariwari

jam operasional bandar udara yang hanya sampai pukul 5 sore. Penggunaan cahaya alami meminimalisir penggunaan energi yang berlebihan. Tidak hanya itu, elemen transparan memungkinkan interaksi antara sisi dalam dan luar bangunan, sehingga Kariwari dihadirkan pada fasad yang dtunjukkan pada Gambar 5. Penggantian material juga mempengaruhi warna-warna yang digunakan. Warna-warna yang membumi dipilih untuk menggambarkan kondisi rumah tradisionalnya yang berbaur dengan alam sekitar terlebih dengan pemandangan Gunung Cycloop pada sisi utara bangunan. 


\section{HASIL RANCANGAN}

Transformasi atap Kariwari hadir sebagai wujud olahan bentuk tradisional lokal sebagai poin utama pada area kerb yang terlihat pada Gambar 4 dan Gambar 7. Kerb sebagai tempat pertemuan arus penumpang merupakan tempat strategis untuk menempatkan wajah ikonik tersebut. Atap Kariwari yang telah ditransformasi merupakan penanda area kedatangan dan area keberangkatan. Selain untuk menghadirkan suasana sedang berada di dalam Kariwari, hal ini memiliki nilai filosofi bahwa orang-orang tiba di kota disambut oleh Rumah Kariwari. Hal yang sama berlaku pada mereka yang berangkat meninggalkan kota diantarkan dan dilepas melalui Rumah Kariwari.

Selain atap yang menggambarkan gugus bangunan, sifat linier gugus bangunan juga dihadirkan melalui siluet Kariwari pada fasad bangunan. Telihat pada Gambar 5, siluet Kariwari yang dibalik hadir sebagai view deck. Selain mendukung fungsinya sebagai view deck, bentuk Kariwari yang dibalik merupakan perumpamaan orang-orang berjalan melalui Keramba sebagai bagian bawah dari Rumah Kariwari.

Salah satu perubahan pada interior ruang dengan penambahan penghijauan yang tampak pada Gambar 6 . Adapun penempatan taman indoor pada bagian dalam ruang tunggu untuk mempertahankan penghijauan yang sebelumnya ada pada terminal lama. Tanaman palempaleman dipilih karena ketahanan dan perawatan yang tidak terlalu sulit. Jenis tanaman tersebut juga menggambarkan kesan tropis Jayapura di dalam ruangan. Disamping itu juga sebagai bentuk simbolisasi kota Jayapura yang masih hijau.

\section{KESIMPULAN}

Identitas sebagai esensi dan ciri khas suatu hal perlu dilestarikan karena kehadirannya yang membuat sesuatu menjadi berbeda dan unik. Identitas nusantara merupakan identitas kelokalan yang perlu dilestarikan agar tidak hilang dalam arus globalisasi yang begitu pesat. Sehingga, diperlukan penyelarasan antara perkembangan zaman dan identitas yang ada agar tidak terkikis dan menghilang begitu saja. Hal tersebut diharapkan mampu menghasilkan paduan yang harmonis antara kelestarian jati diri dan kebutuhan akan zaman terus berubah.

\section{DAFTAR PUSTAKA}

[1] A. Imelda, Wiratman Architecture Airport Design. Jakarta: Imaji (2016) 13-15.

[2] Direktorat Jenderal Perhubungan Udara Kementerian Perhubungan Republik Indonesia. Bandar Udara Sentani. http://hubud.dephub.go.id/?id/bandara/detail/26 diakses pada 9 Novermber 2016 14:21.

[3] P. Josef, 35 Karya Pilihan PROPAN, Sayembara Desain Arsitektur Nusantara "Eksplorasi Desain Arsitektur Nusantara". Jakarta: PT. Prima Info Sarana Media (2014) 14-25.
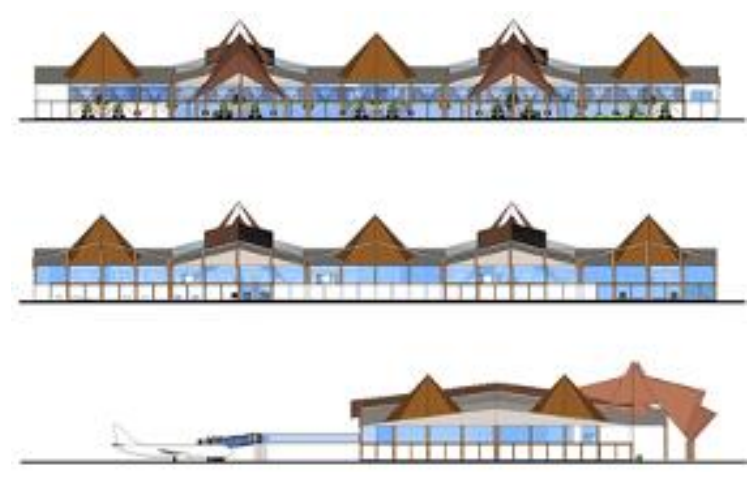

Gambar 4. Tampak bangunan

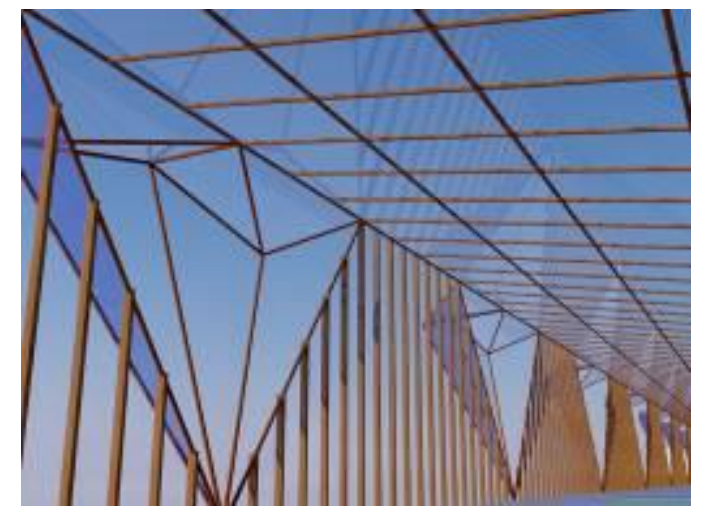

Gambar 5. Detil koridor lantai dua

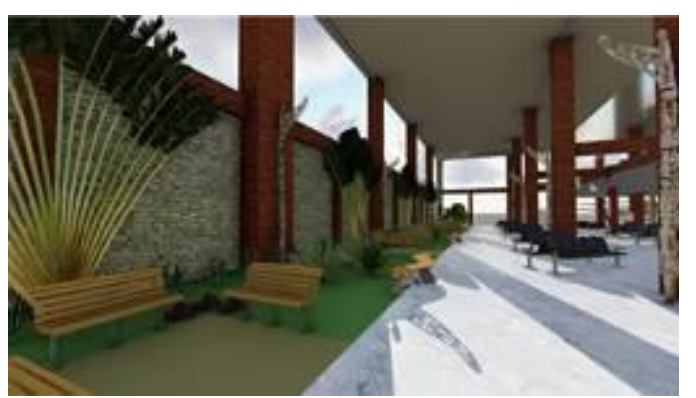

Gambar 6. Taman indoor ruang tunggu keberangkatan

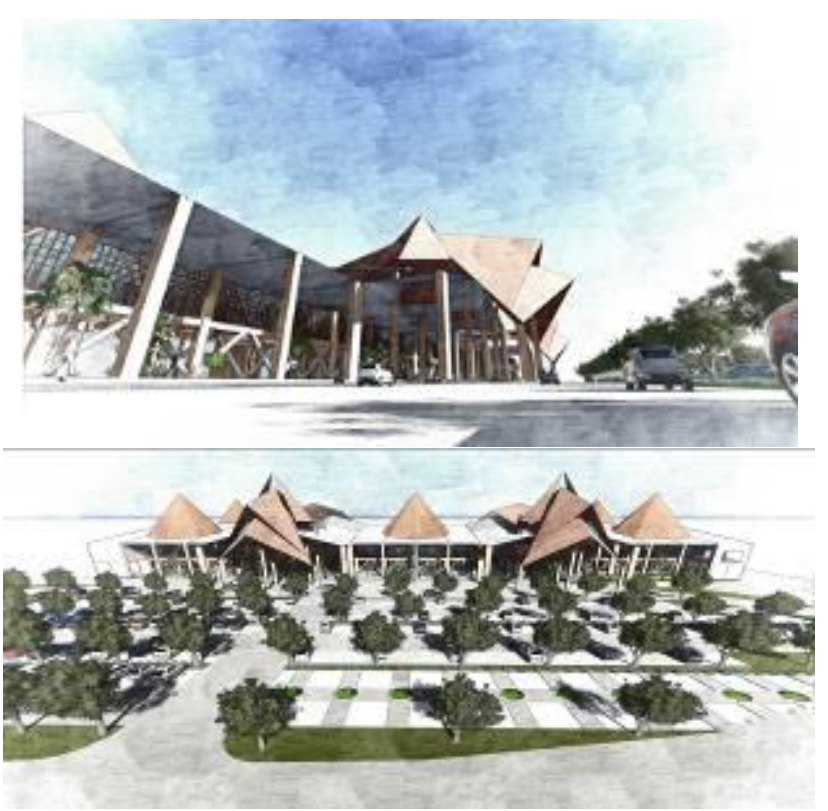

Gambar 7. Perspektif 